\title{
A comunicação como via de inclusão social nos museus
}

Cristiane Batista Santana

Especialista em Gestão da Comunicação.

Assessora de comunicaşão da Fundação Energia e Saneamento.

E-mail: cristabem@yahoo.com.br

Resumo: Este artigo apresenta uma análise sobre o potencial da comunicação nos museus para um trabalho de inclusão social, a partir de um projeto de Gestão da Comunicação vislumbrando as possibilidades de se estabelecer uma comunicação dialógica entre o Museu da Energia de São Paulo e grupos de seu entorno. A pesquisa desenvolvida fundamentou a proposição de estratégias de atuação para que os diversos grupos e entidades sociais de seu entorno se apropriem deste espaço comunicativo e de mediações.

Palavras-chave: museu, comunicação, comunicação museológica, mediação, comunicação e cultura.
Abstract: This article introduces an analysis on the potencial of communication in museums for social inclusion actions, departing from a Communication Management project. It outlines possibilities of stablishing a dialogic communication between the Museu da Energia de São Paulo and groups of its surroundings. The research developed for the project based the proposal of strategies to take that as a communicative and mediation space by the various groups and social entities of the surroundings.

Keywords: museum, communication, museológica communication, mediation, communication \& culture.

A comunicação como instrumento de mediação entre museus e contexto social em que estão inseridos foi tema da pesquisa que desenvolvi no curso Gestão da Comunicação da Escola de Comunicações e Artes da Universidade de São Paulo para o Museu da Energia de São Paulo.

Ao tratar de um tema tão estudado na Museologia, acabamos por identificar como a comunicação adquire função essencial e estratégica, no sentido de promover o diálogo e induzir a inserção de grupos que vivem problemas sociais e possuem interesses distintos.

Jesús Martín-Barbero argumenta que existem três campos de investigação estratégicos em comunicação: "el orden o estructura internacional de la información, el desarrollo de las tecnologías que fusionan las telecomunicaciones con la informática, y la llamada comunicación participativa, alternativa o popular". ${ }^{1}$

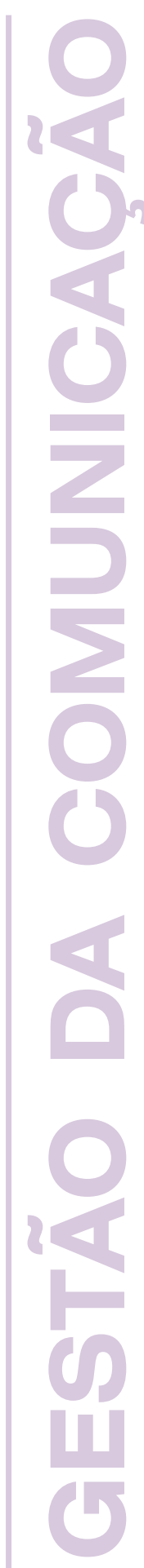

Recebido: 25.03.2008

Aprovado: 15.07.2008

1. MARTÍN-BARBERO, Jesús. Procesos de comunicación y matrices de cultura. México: Gustavo Gilli, 1987. p. 90. 
Definir o que é alternativo em matéria de comunicação na América Latina, para Martín-Barbero, é "transformar el proceso, la forma dominante y normal de la comunicación social, para que sean las clases y los grupos dominados los que tomen la palabra"2.

Este artigo considera a possibilidade de relacionar outras vozes e trazer outras mediações para o museu, a partir da relação com a população dos arredores.

Entendemos que não podemos deturpar o conceito de popular adotado por Martín-Barbero e atribuir a ele um sentido de marginalidade vinculado à pobreza. A ligação com o popular existe ao situarmos que se trata de uma investigação não-convencional que "coloca la cultura como mediación, social y teórica da la comunicación”’3.

\section{O MUSEU DA ENERGIA DE SÃO PAULO E SEU CONTEXTO}

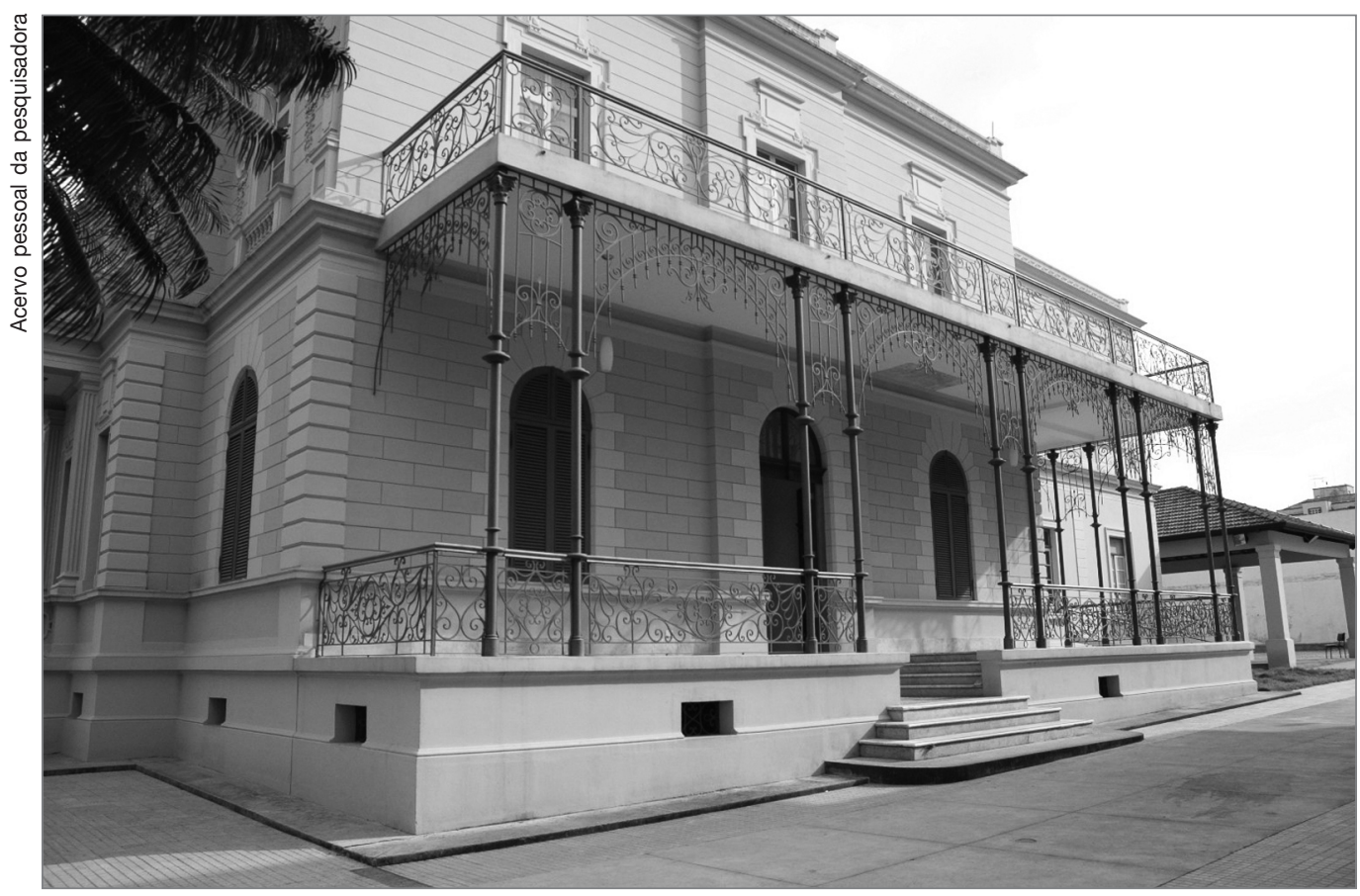

Museu da Energia de São Paulo, 7/4/2007.

Inaugurado em junho de 2005, o Museu da Energia de São Paulo é um dos equipamentos culturais da Fundação Patrimônio Histórico da Energia e Saneamento - instituição privada, sem fins lucrativos, criada para preservar e divulgar o patrimônio histórico do setor de energia e de saneamento. Está localizado na Alameda Cleveland, 601, no bairro de Campos Elíseos, próximo aos bairros da Luz e do Bom Retiro, região central da cidade de São Paulo. 
Trata-se de uma instituição jovem, que oferece ao público mostras e exposições sobre a história da energia e seus impactos na sociedade, enfatizando os processos de urbanização e industrialização promovidos pelo advento da eletricidade.

A partir de 2009, o Museu deverá abrigar uma exposição de longa duração de caráter histórico-tecnológico, abordando os temas da urbanização e industrialização, hábitos e costumes ligados ao uso da energia elétrica, ao consumo e à eficiência energética. Serão apresentadas as principais fontes convencionais e alternativas, bem como as tendências futuras relacionadas ao uso da energia.

Em seu projeto museológico desenvolvido em 2007, foi estabelecido, entre outras diretrizes, o atendimento a grupos marginalizados de instituições culturais como, por exemplo, o de "moradores e a população de risco da região"4. Mas como fazer isso? De que maneira?

As desigualdades sociais e a decadência da região central da cidade, provocadas pela ausência de políticas públicas articuladas, fazem desse entorno (bairros de Campos Elíseos, Luz e Bom Retiro) território de complexidades que geram grandes desafios para inserir o museu como agente atuante no contexto social. Algumas das tensões se manifestam nas ocupações de prédios abandonados e novas ondas de imigrações de coreanos, chineses e de latino-americanos, sobretudo bolivianos, peruanos e paraguaios.

A região passa por uma política de revitalização excludente a grupos menos favorecidos economicamente, cedendo grandes lotes de área e imóveis à especulação imobiliária por meio de incentivos fiscais ${ }^{5}$. Paralelamente, Luz, Bom Retiro e Campos Elíseos constituem um grande polo cultural na cidade, congregando cerca de dezessete instituições culturais, entre elas a Pinacoteca do Estado, o Museu da Língua Portuguesa e o próprio Museu da Energia de São Paulo.

Para o desenvolvimento do projeto de intervenção, partimos do pressuposto de que toda instituição cultural está inserida no social e não deve ignorá-lo como parte do cumprimento de sua função na sociedade. Assim, desenvolvemos estudo, identificando e analisando as alternativas e os processos de comunicação que envolvem o Museu da Energia de São Paulo e as comunidades do entorno, pensando essa comunicação de maneira dialógica, e considerando que existe a complexidade desse entorno.

\section{O CONCEITO DE CULTURA E SUA RELAÇÃO COM A COMUNICAÇÃO}

Para tratarmos dessa complexidade, buscamos alguns conceitos que nos abriram perspectivas sobre o entendimento de cultura na sua relação com a comunicação. Geertz nos traz essa ligação entre comunicação e cultura a partir de um olhar semiótico:
4. MUSEU DA ENERGIA de São Paulo. Plano museológico e educativo do Museu da Energia. São Paulo, 2007. Mimeografado.

5. A Lei n. 14.096 estimula a instalação de empresas de tecnologia e outros serviços, estabelecendo um perímetro de incentivo fiscal. Disponível em: <http://www.prefeitura.sp.gov.br/nova_luz/ lei14096.asp >. Acesso em 16/7/2008. 
6. GEERTZ, Clifford. A interpretação das culturas. Rio de Janeiro: Zahar, [s.d.]. p. 15.

7. VELHO, Gilberto; CASTRO, Eduardo B. Viveiros de. O conceito de cultura e o estudo de sociedades complexas. Revista Artefacto, ano 1, v. 1, p. 22, [s.d.].

8. RÜDIGER, Francisco. Comunicação e Teoria Social Moderna. Porto Alegre: Fênix, 1995. comunicação \& educação • Ano XIV • Número 1 • jan/abr 2009

Acreditando, como Max Weber, que o homem é um animal amarrado a teias de significados que ele mesmo teceu, assumo a cultura como sendo essas teias e sua análise; portanto, não como uma ciência experimental em busca de leis, mas como uma ciência interpretativa, à procura do significado ${ }^{6}$.

O significado é o produto da comunicação. É o sentido que se atribui a um dado discurso, uma imagem, um signo posto no social, em comunicação.

Velho e Castro apontam para essa perspectiva, quando colocam a possibilidade de entender cultura como um código: "Entendendo-se cultura como um código, um sistema de comunicação, percebe-se o seu caráter dinâmico ao produzir interpretações, significados, símbolos diante de uma realidade em permanente mudança" 7 .

Em um sistema de comunicação, quer seja ele verbal, quer não-verbal, códigos são lançados à interpretação, manipulação, negociação entre indivíduos; e é nessa batalha por sentidos que um jogo de forças se estabelece na atual sociedade, em que fronteiras se abrem e se fecham constantemente.

Portanto, partimos de um entendimento de cultura como um sistema de produção de significados compartilhados e negociados por indivíduos, grupos de indivíduos jamais apartados das instâncias e relações de poder que permeiam a vida social.

A comunicação desempenha um papel fundamental nesse processo, buscando entender os significados culturais contidos nos usos possíveis dos espaços de sociabilidade compartilhados por indivíduos.

É a partir da capacidade de nos comunicarmos que somos capazes de viver socialmente, de nos relacionarmos e compartilharmos experiências. A comunicação é, portanto, um processo constante de negociação dos sentidos feita por diversas mediações na relação do sujeito com o mundo. Sendo ela um "processo generalizado de mediação da práxis humana", não podemos pensá-la de forma dissociada da cultura e do contexto social em que vivemos.

\section{A MUSEOLOGIA EM BUSCA DA RELAÇÃO MUSEU-COMUNIDADE}

A museóloga Maria Célia entende o museu como um fenômeno social que tem o seu papel social a desempenhar. Ela pesquisou documentos resultantes de diversos encontros realizados pela Unesco e pelo Comitê Internacional dos Museus (ICOM), entre 1958 e 1971, dentre os quais destacamos as conclusões apresentadas pela IX Conferência do ICOM, realizada em Paris e Grenoble, em 1971:

Era necessário, pois, redefinir a missão dos museus, seus métodos de exibição das coleções e, talvez, quem sabe, buscar um novo modelo para a instituição. [...] Enfatiza-se também a necessidade de interação do museu com o meio onde está inserido, destacando-se a realização de programas que abordem os problemas da vida cotidiana, 
buscando a realização de atividades conjuntas com sindicatos, cooperativas do meio rural, fábricas etc. ${ }^{9}$

Como podemos perceber, a discussão da relação dos museus com seu entorno não é nova para o campo da Museologia. Entretanto, desejamos saber como o campo da Comunicação pode contribuir com essa discussão.

É nesse ponto que o problema de nosso projeto de pesquisa se evidencia: Como desenvolver e estabelecer uma comunicação entre o Museu da Energia de São Paulo e as comunidades de seu entorno, marginalizadas de instituições culturais, de maneira dialógica, considerando a realidade conflituosa e a diversidade destas comunidades e os limites do Museu da Energia de São Paulo enquanto equipamento cultural?

\section{SELECIONANDO A AMOSTRA, ENTRANDO NA PESQUISA}

Para tratar deste problema, realizamos uma pesquisa empírica em que ouvimos alguns atores sociais, selecionando uma amostra não-probabilística ${ }^{10}$, levando em consideração a vulnerabilidade social e a pluralidade cultural local. Segundo Lopes, esse tipo de amostra é tida como significativa ou de representatividade social (não-estatística), e os métodos de tratamento de dados são qualitativos.

Grupo 1 - Mulheres que trabalham com coleta seletiva em uma cooperativa da região central: a Coopere. Olinda, Socorro e Tatiana possuem idades variadas e o grau de escolaridade é o ensino fundamental completo.

Grupo 2 - Imigrantes latino-americanas com idades variadas. Estão no Brasil de maneira regularizada. Jobana é boliviana e Isabel, peruana.

Grupo 3 - Representantes de três entidades sociais que atuam na região do Bom Retiro: Centro de Apoio ao Migrante (CAMI); Centro Gaspar Garcia de Direitos Humanos (CGGDH), entidade à qual a Coopere está vinculada; e Associação dos Nordestinos do Estado de São Paulo (Anesp). Cabe ressaltar que duas dessas entidades serviram como mediadores da visita ao Museu da Energia: o CAMI, no caso das latino-americanas, e o CGGDH, no caso das catadoras.

Grupo 4 - Composto de três instituições culturais da região (Pinacoteca do Estado de São Paulo, Sala São Paulo e Museu da Língua Portuguesa). Entrevistamos profissionais que coordenam programas educativos e culturais para conhecer as experiências da instituição com grupos sociais do bairro e o papel que a área cultural tem no contexto social local.

\section{As técnicas de coleta de dados na pesquisa}

Os dois primeiros grupos foram submetidos à observação direta ao longo de uma visita realizada à exposição intitulada Fazer a energia: memórias, trabalho e luz, no Museu da Energia de São Paulo, nos dias 25 de abril, 8 e
9. SANTOS, Maria Célia Teixeira de Moura. Museu e comunidade: uma relação necessária. 13a Reunião Anual do Instituto Biológico, São Paulo, de 6 a 11 de novembro de 2000. São Paulo: 2000 , p. 3. Mimeografado. Grifos da autora.

10. Ver: LOPES, Maria Immacolata V. Pesquisa em comunicação. 8. ed. São Paulo: Loyola, 2005. 
comunicação \& educação • Ano XIV • Número 1 • jan/abr 2009

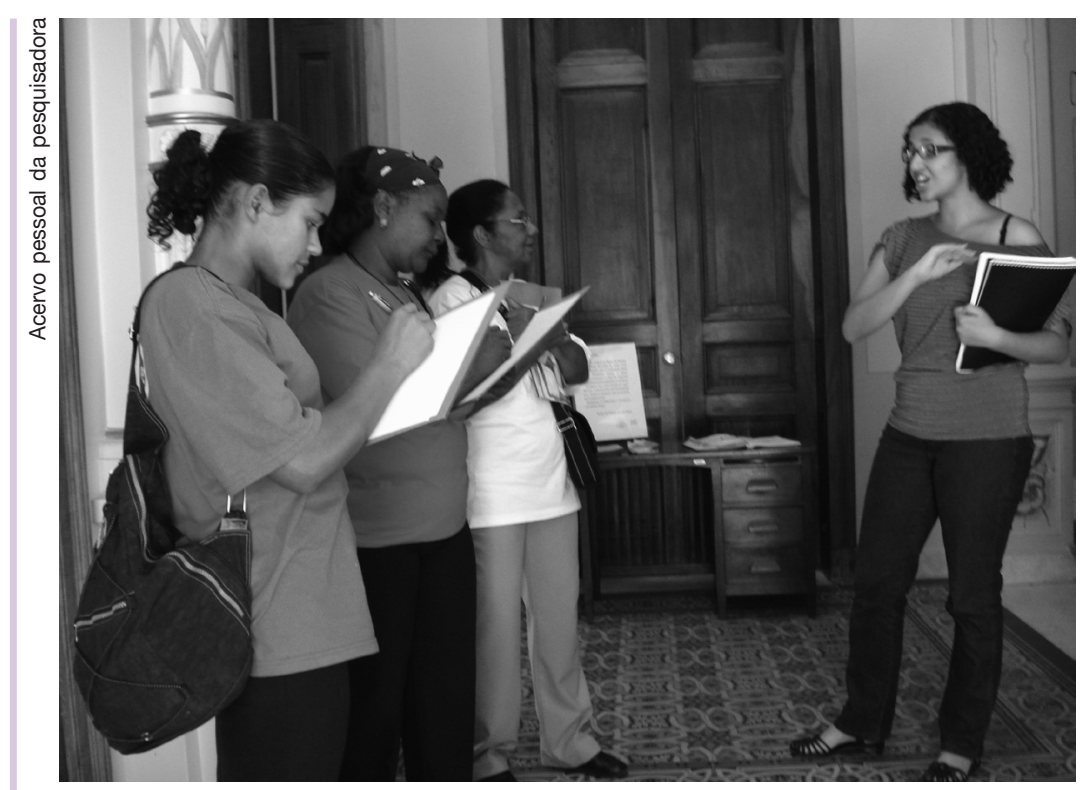

As visitantes, trabalhadoras da Coopere, anotam informações sobre o Casarão. 25/4/2008

14 de maio de 2008, contando com a participação direta da pesquisadora na realização de entrevista ao final da visita.

Com o grupo 3 (entidades sociais), realizamos uma entrevista na sede da própria entidade social, a qual foi estratégica para coletar dados relativos aos interesses e expectativas quanto às instituições culturais.

Em relação ao grupo de instituições culturais, a técnica de coleta foi a aplicação de entrevista para avaliar a existência de algum programa, ou que tipo de ligação mantém com o entorno.

\section{PRINCIPAIS RESULTADOS, SAINDO DA PESOUISA}

A pesquisa atingiu os objetivos propostos, gerando dados bastante significativos que puderam ser analisados e interpretados. Destacamos alguns a seguir.

O grupo de catadoras associou o museu com um espaço para apropriação de conhecimento, e realizou a visita de maneira bastante participativa, interagindo com a educadora por meio de muitas perguntas (Que lugar é esse aqui?, Essa obra ainda existe? etc.).

Nos aspectos gerais, o lazer cultural não é parte do cotidiano dos grupos sociais. Todas as pesquisadas já tiveram algum tipo de contato com museus, mas, sobretudo, para as catadoras, eles causam a impressão de ser um espaço proibido socialmente.

A evidência dessa constatação pode ser notada em algumas falas de Socorro:

A maioria dos equipamentos públicos, você passa na porta e já vem um segurança, um guarda, por isso nunca tive curiosidade de descobrir, de saber o que realmente era. 


\section{E de Olinda:}

Quando a gente vê um guarda, a gente tem a sensação de que não é para entrar.

A apropriação do espaço do museu por parte das imigrantes latinas nos indicou ainda que é compreendido como o lugar de uma cultura local. Jobana, imigrante boliviana, falou sobre a dificuldade de inserção cultural dos bolivianos e acredita que os museus podem fazê-los conhecer e compreender melhor a cultura brasileira:

Um museu mostra tanto de um povo, tanto de uma pessoa... ajuda os bolivianos não ficarem tão fechados e falar que todo o povo brasileiro é ruim, porque não é assim.

As entidades sociais que trabalham com esses grupos realizam atividades culturais - como visitas a museus - de maneira bastante esporádica e reconhecem alguma importância na área cultural para o trabalho social que praticam, mas desejam que a iniciativa da aproximação ocorra por parte das instituições culturais.

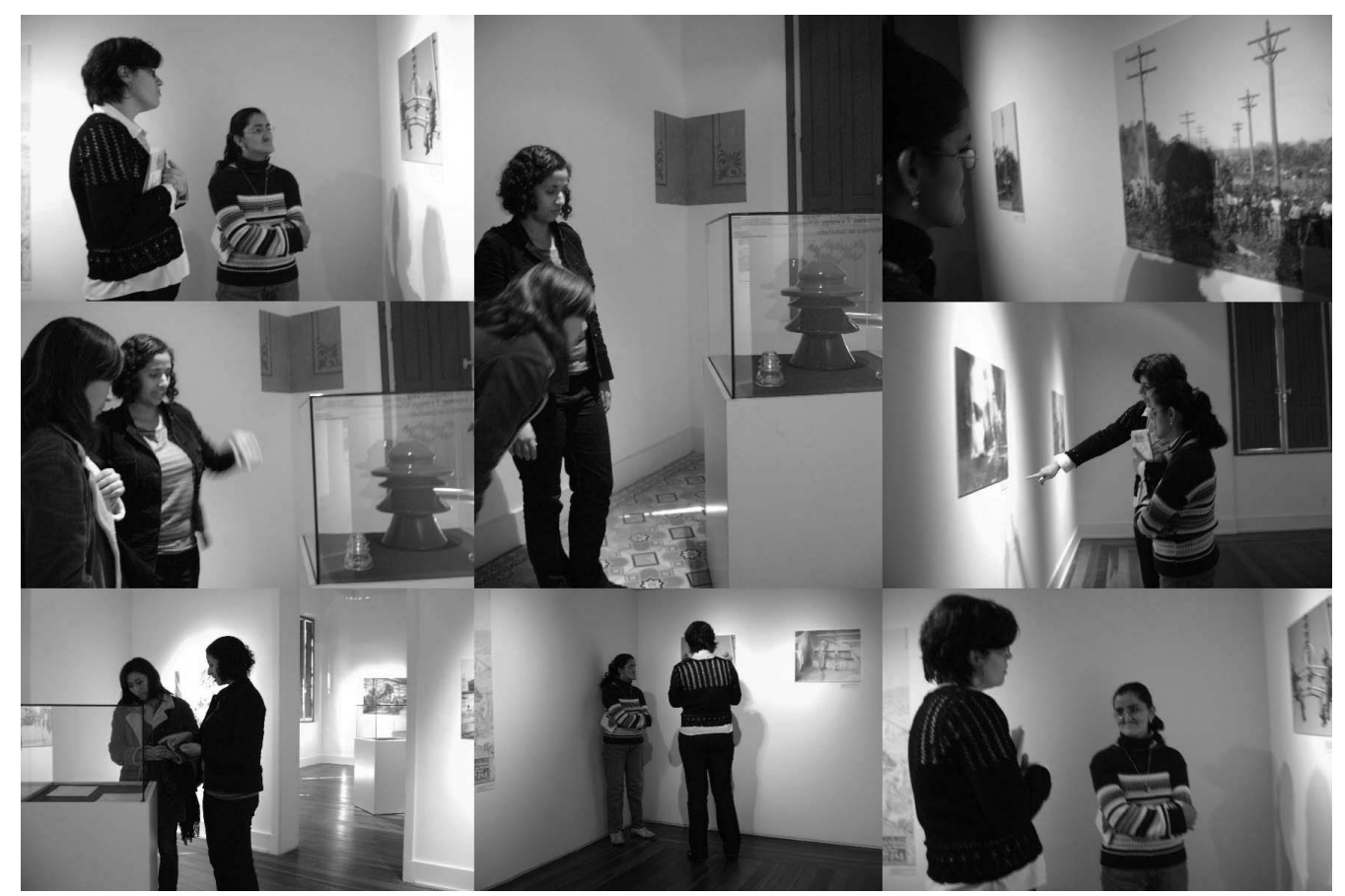

Imagens da boliviana Jobana Moya (canto inferior à esq.) e da peruana Isabel C. Torres (canto inferior à dir.), em visita ao Museu da Energia, nos dias 8/5/2008 e 15/5/2008, respectivamente.

Por sua vez, as instituições culturais, de um modo geral, têm ciência sobre o contexto social conflituoso ao qual estão inseridas, e, das três pesquisadas, duas delas consideram que o museu deve contribuir com o desenvolvimento social local, ainda que individualmente.

Tanto as entidades sociais como as próprias instituições culturais notam a necessidade de haver algum diálogo entre os museus, centros e oficinas 
comunicação \& educação • Ano XIV • Número 1 • jan/abr 2009

culturais da região. Há o entendimento comum de que as políticas públicas de revitalização empreendidas na região não contentam aos grupos e entidades sociais e instituições culturais.

Na pesquisa, o confronto de visões se estabelece quando, de um lado, as entidades sociais esperam que as instituições culturais se aproximem com propostas e, de outro, encontramos nestas últimas uma relação autoritária com o entorno, quer seja pela comunicação visual, que não é convidativa à população local, quer seja por uma visão de que o meu público tem medo do que está lá fora. Nesse confronto, cada um se vê como o Outro, o nãopertencente a um dado contexto social, com o qual cada um com a sua natureza e finalidade institucional tem algo a contribuir.

Todos estão necessitando dessa via de conexão, obstruída pela projeção ao Outro da responsabilidade pela formulação de alternativas que atuem na transformação de uma dada realidade. Nesse aspecto é que reside o papel estratégico da comunicação: para haver diálogo é preciso reconhecer quais são as fronteiras que separam e que conectam os grupos e indivíduos.

Desse modo, o significado que reconhecemos da comunicação nos museus é de que ela pode servir como instrumento de mediação da relação passado/presente, interno/externo, cultural/social, local/global.

Se, como na visão de Cristina Costa, "a comunicação é a ponte que integra subjetividades através de ferramentas de linguagem - os signos, as técnicas e tecnologias comunicativas" ${ }^{11}$, é possível construir, pela comunicação, uma ponte entre dois conhecimentos: o que está dentro e fora do museu?

\section{PROPOSTA DE INTERVENÇÃO}

No projeto de intervenção apresentado neste artigo, a proposição de estratégias de atuação para que esse museu seja inserido no contexto social local, e para que os diversos grupos e entidades sociais se apropriem deste como espaço comunicativo de mediações, resultou numa série de ações - das quais destacaremos algumas - que pretendem contribuir com o aperfeiçoamento da Política Cultural do Museu da Energia de São Paulo.

\section{DIÁLOGO COM O PÚBLICO}

\section{a) Via Exposição de Longa Duração (público em geral)}

A exposição de longa duração deverá favorecer a pluralidade de lin-

11. COSTA, Cristina. Ficção, comunicação e mídias. São Paulo: SENAC, 2002. p. 12. uagens, experiências e sensações para que o visitante não seja um mero usuário, e sim um agente participante. Os meios ou a utilização dos multimeios em uma exposição devem ser entendidos como agências de mediação de informação entre a exposição/visitante. Entendidos desta forma, eles podem 
ser utilizados tanto na exposição como enquanto recursos pedagógicos nas atividades educativas.

\section{b) Via Exposição de Curta Duração (público do entorno)}

Com base no princípio de que

a) "a comunicação só se efetiva quando ela é incorporada e se torna fonte de outro discurso"12;

b) a comunicação envolve a pluralidade de discursos e de vozes; e

c) o museu serve como mediador da relação passado/presente, interno/ externo,

propomos que a montagem de exposições de curta duração possa ser orientada para o diálogo e para a inserção de grupos sociais do entorno, privilegiando a sua situação de vulnerabilidade social e a multiculturalidade desses grupos, que vivem, trabalham e formam o distrito do Bom Retiro.

Os grupos deverão estar vinculados a alguma entidade que atue na região do entorno do Museu para a construção de uma exposição da qual possam participar de sua concepção, planejamento e execução, trabalhando com o eixo norteador da energia e seus desdobramentos (história, meio ambiente e ciência), buscando sempre a conexão direta com o cotidiano. Por exemplo, os catadores da região utilizam a sua energia humana para o reaproveitamento de materiais e, assim, reduzem o desperdício de energia elétrica na produção de novos materiais, contribuindo para a redução de medidas de grandes impactos ambientais.

Desse modo, o Museu estaria trazendo outros discursos para o seu interior e fazendo com que os grupos produzam seu conhecimento, estimulandoos a utilizar o próprio acervo da Fundação/Museu. Ao final, as exposições inauguradas no Museu da Energia poderão itinerar pelas entidades sociais para que divulguem as empresas parceiras e financiadoras de seus projetos.

O Museu da Energia também poderá complementar essa ação formando os agentes sociais que atuam com esses grupos e tornando-os seus mediadores culturais, por meio de oficinas de formação que irão habilitá-los para trabalhar com os conteúdos das exposições, estimulando-os a fazerem conexões entre os temas das mostras e o trabalho social que realizam.

\section{c) Via atividades/eventos culturais}

Objetivando manter uma relação mais estreita com os visitantes, o Museu poderá produzir uma newsletter com conteúdos elaborados pela equipe de educadores e de comunicação, procurando trazer temas das exposições e experiências dos visitantes. O Museu da Energia de São Paulo também pode promover uma aproximação com as instituições culturais e sociais da região, enviando-lhes convites para eventos, bem como
12. BACCEGA, Maria Aparecida. Comunicação e linguagem: discursos e ciência. São Paulo: Moderna, 1998. p. 104. 
comunicação \& educação • Ano XIV • Número 1 • jan/abr 2009

oferecendo seu espaço para a realização de ações culturais lançadas por tais entidades, como oficinas de coleta seletiva ou de técnicas artísticas a partir de materiais recicláveis.

\section{CRIAÇÃO DE ESPAÇO DIGITAL}

Sabemos que, na atualidade, os meios de comunicação e as tecnologias digitais desempenham uma mediação de contato com o mundo e que a inclusão digital é uma ação desenvolvida por muitas instituições e museus, como alvo de políticas públicas.

Nessa perspectiva, propomos a criação do Espaço Energia. Além de contar com biblioteca e material educativo sobre energia, poderá oferecer à comunidade local acesso à internet com horários livres para utilização e para jogos baseados no tema energia. O espaço pode dar, ainda, oportunidade para que os visitantes possam compartilhar experiências da visita com frequentadores dos outros equipamentos culturais da Fundação, já que a instituição possui uma rede de museus da Energia em atividade, localizados nos municípios paulistas de Itu, Jundiaí, Rio Claro, Salesópolis, além da unidade da capital.

\section{ESTREITAR A RELAÇÃO ENTRE OS MUSEUS DA REGIÃO}

A pesquisa de nosso projeto evidenciou a falta de diálogo entre as instituições culturais da região. Em função disso, propomos a formação de um comitê permanente de instituições culturais da região central, oficializado, com o objetivo de realizar ações conjuntas (atividades de capacitação, intercâmbio técnico e cultural), além de promover visitas de grupos em parceria e uma maior articulação entre as ações sociais, culturais e educativas desenvolvidas por diversas instituições na região. Para tanto, o Museu e a Fundação poderiam atuar como promotores desse movimento.

\section{CONSIDERAÇÕES FINAIS}

O museu é um local de memória, mas não carrega somente o passado, como entende o senso comum. Traz consigo o presente das relações e do contexto social em que vivemos. Carrega fragmentos de múltiplas identidades.

A comunicação é um vetor de conhecimento ao revelar o presente das relações, atuando sobre elas, e evidenciando que o patrimônio histórico encerrado nos museus não assume discursos isentos de ideologias ou das mais diversas mediações. A comunicação pode dar contribuições significativas aos museus nos seus processos de inclusão social e de diversificação de públicos a partir de seu papel indutor de novas narrativas e mediações. Como diz Aidar, podem servir "tanto para incluir segmentos da sociedade quanto para excluí-los e cristalizar preconceitos" ${ }^{\text {"13. }}$. 
A comunicação como via de inclusão social nos museus - Cristiane Batista Santana

Entendendo a comunicação como um processo de mediação e de negociação dos sentidos é que podemos estabelecer uma comunicação inclusiva, tornando o museu não apenas visível, mas presente e vivo na sociedade.

\section{REFERÊNCIAS BIBLIOGRÁFICAS}

AIDAR, Gabriela. Museus e inclusão social. Revista da Faculdade Porto-Alegrense de Educação, Ciências e Letras, n. 31, jan./jun. 2002.

BACCEGA, Maria Aparecida. Comunicação e linguagem: discursos e ciência. São Paulo: Moderna, 1998.

COSTA, Cristina. Ficção, comunicação e mídias. São Paulo: SENAC, 2002.

GEERTZ, Clifford. A interpretação das culturas. Rio de Janeiro: Zahar, [s.d.].

LOPES, Maria Immacolata V. Pesquisa em comunicação. 8. ed. São Paulo: Loyola, 2005.

MARTÍN-BARBERO, Jesús. Procesos de comunicación y matrices de cultura. México: Gustavo Gilli, 1987.

MUSEU DA ENERGIA de São Paulo. Plano museológico e educativo do Museu da Energia. São Paulo, 2007. Mimeografado.

RÜDIGER, Francisco. Comunicação e Teoria Social Moderna. Porto Alegre: Fênix, 1995.

SANTOS, Maria Célia Teixeira de Moura. Museu e comunidade: uma relação necessária. 13a Reunião Anual do Instituto Biológico, São Paulo, de 6 a 11 de novembro de 2000. São Paulo, 2000. Mimeografado.

VELHO, Gilberto; CASTRO, Eduardo B. Viveiros de. O conceito de cultura e o estudo de sociedades complexas. Revista Artefacto, ano 1, v. 1, [s.d.].

\section{Endereço eletrônico}

$<$ http://www.prefeitura.sp.gov.br/nova_luz/lei14096.asp $>$.

Acesso em 16/7/2008. 


\section{O ensino pelo diálogo, um exercício necessário}

\author{
Re-despertar a dignidade em cada ser, quase \\ sempre esquecida pela sociedade de hoje. \\ Este é o desafio do educar!
}

Educação transpessoal Um jeito de educar a partir da interioridade Jorge Trevisol

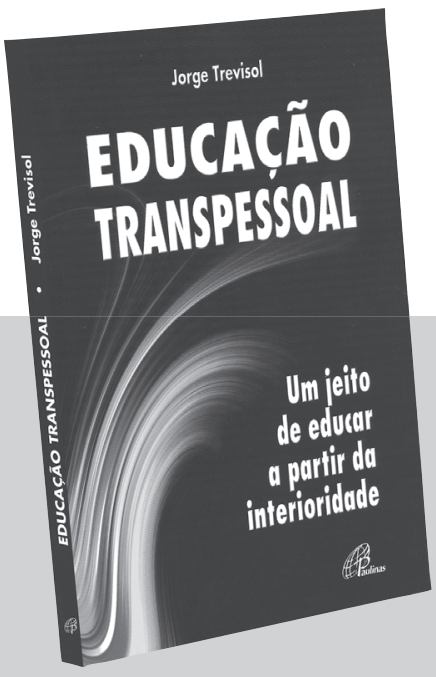

Educar a partir de dentro, da consciência do profundo, das motivações internas, do sagrado que habita o coração. Trevisol propõe um educar que exige desprendimento, entrega, humildade e confiança, a fim de modificar o modo de se perceber além dos sentimentos, naquele espaço em que não haverá nem pensamentos nem sensações nem comportamentos, somente o essencialmente sagrado e puro: a inteireza de tudo.

Código: 5I4306 Págs: 208 ISBN: 9788535623|47
Propostas metodológicas para professores reflexivos Como trabalhar com a diversidade em sala de aula

Mercedes Blanchard e María Dolores Muzás

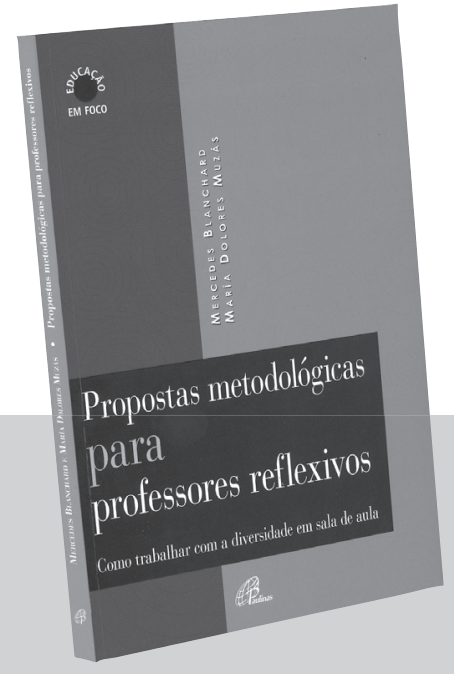

Além de discutir as demandas que emergem no ambiente escolar, as autoras sugerem atividades para que os docentes reflitam sobre a proposta educativa e busquem respostas na práxis de educador, questionando o que se faz e como se faz, sempre com a teoria em diálogo com a prática. Questionam quem são os verdadeiros protagonistas na tarefa de ensinar e falam da necessidade de lançar um olhar mais atento ao aluno, para desvendar o que se passa em sua mente, suas emoções, etc. e oferecem respostas para apoiar o processo de ensino-aprendizagem. Estratégias organizativas e metodológicas e ações já testadas complementam o ensaio.

Código: 5 | 3784 Págs: 216 ISBN: 9788535622485 